\title{
Homophobia and heterosexism: Spanish Physical Education teachers' perceptions
}

\author{
Joaquín Piedra*
}

Department of Physical Education and Sport, University of Seville, Seville, Spain

Gonzalo Ramírez-Macías

Department of Physical Education and Sport, University of Seville, Seville, Spain

Francis Ries

Department of Physical Education and Sport, University of Seville, Seville, Spain

Augusto Rembrandt Rodríguez-Sánchez

Centro de Estudios Profesionales, Fundación CEU San Pablo Andalucía, Bormujos, Spain

Catherine Phipps

University of Greenwich, London, UK

* Corresponding author:

jpiedra@us.es

Facultad de Ciencias de la Educación

C/ Pirotecnia s/n

41013 Sevilla (Spain) 


\title{
Homophobia and heterosexism: Spanish physical education teachers' perceptions
}

\begin{abstract}
Physical education is traditionally a heteronormative environment, despite current studies highlighting the existence of positive changes in sport towards sexual diversity. In Spain, physical education teachers' attitudes towards sexual minorities are an under-researched area. The current study identifies physical education teachers' perceptions towards homophobia and heterosexism in their lessons, raising questions as to whether societies are hostile or more tolerant in regards to gays and lesbians in sport. This experimental and cross-sectional descriptive research involved 170 Physical Education teachers from mixed schools, using a modified version of the original questionnaire of homophobia and heterosexism perceptions by Morrow and Gill (2003). Results show heterosexist and homophobic behavior is apparent in physical education lessons, with teachers aware of these behaviours. Furthermore, it is highlighted that students use homosexually-themed language as an instrument to discriminate against gays and lesbians. This language use is not common among teachers, although when it is present, it is clearer and more frequent amongst male teachers.
\end{abstract}

Key words: Physical education, teachers, homosexuality, gender discrimination, sexism

\section{Introduction}

Physical education (PE) at school is an important tool for improving students' identities through their bodies. As Vidiella $(2007,3)$ states, "embodiment will be key in order to understand how people face rules or resist them". The body and movement play a key role in the relations between students within society. PE is fundamental for education through the body and is necessary to develop and create understanding of students' sexual identities. Nevertheless, until now PE has been fundamental in imposing objective body attributes in accordance with ethical, moral and ideological theories of the dominant classes, while failing to deal with diversity (Vicente 2010). Within PE, teachers play a key role in gender treatment (Scraton 2013), and have potential to create a safe and discrimination-free environment for all students. Spain is predominantly made up of mixed-schools, with only 219 single-sex education schools among 28,064 recognized by the European Association of Single-Sex Education in 2012 (Ministerio de Educación, Cultura y Deporte 2014). Spanish teachers can (and must) fight against discrimination 
in their lessons, eliminating the barriers that boys and girls face to practice PE freely and safely. Educational legislation in Spain provides these guidelines; however PE teachers are often not motivated to accept them (Piedra, García-Pérez, Fernández-García and Rebollo, 2014).

The aim of our study is to identify Spanish PE teachers' perceptions towards homophobia, heterosexism and inclusion in their lessons, and increase knowledge of the problems that PE teachers find in mixed environments in regard to gay and lesbian pupils. The results of the present study, in line with previous studies undertaken in Spain (Piedra, Ramírez-Macías, and Latorre 2014; Piedra et al. 2013), allow us to make a more accurate diagnosis of the reality of heterosexism and homophobia in Spanish PE, and search for more effective solutions.

\section{The boundaries of heteronormativity in physical education: Teachers and homosexuality}

The traditional patriarchal gender order has historically developed within western societies. Within this social system, there are two factors that permeate many social activities: homophobia and heterosexism. Several studies link homophobic and heteronormative behaviours with environments where traditional gender roles are maintained (Plummer 1999). Hence the power dynamics around sexuality play an important role in building, continuing, or breaking the gender order and its hierarchy (Connell, 1995).

Nowadays, homosexuality is widely studied from different academic fields. For some people, homosexuality creates much controversy and fear. The fear of homosexuality, irrational in many cases, is often referred to as homophobia. Anderson (2009) also discusses the concept of homohysteria, understood as the fear of being considered homosexual. McCormack and Anderson $(2014,153)$ state that "homohysteria conceptualizes the contexts when homophobia effects (or is used to police) heterosexual men's gendered behaviors" and affirm that "societies evolve through three periods depending on homophobia and homohysteria: from a period of homo-erasure to homohysteria and finally to a period of inclusivity". Therefore, it is necessary to consider the social context in which research takes place, to accurately understand and explain the realities of homophobia and homohysteria.

Another pillar of a heteronormative environment is heterosexism, which is defined as the belief that everybody is heterosexual, with this sexuality considered the norm. This leaves homosexuality and other sexual orientations in a devalued and discredited position since they exceed the limits of heteronormativity (Hyde and Delamater 2006). As Herek (1996) notes, 
heterosexism and homophobia run in parallel to antigay feelings and feed on themselves. Heterosexism favors the idea that heterosexuality is natural and other sexual orientations are abnormal, with homophobia regarded as a direct consequence of this attitude (Dreyer, 2007; Pharr, 1997). Likewise, as Kian et al. (2013) point out, heterosexism forms the basis of homophobic behaviors, which are the pillars of the don't ask, don't tell culture, in which gay athletes' sexual identities are often not treated on par with that of heterosexual athletes. As Anderson $(2002,847)$ states "heterosexual discourse is so pervasive in sport that it subtly leads gay athletes to feel that they have no right to discuss their sexuality, despite the overflowing discussions of heterosexuality around them". These relationships have been previously studied in the sport context (Lenskyj, 2013; Nylund, 2004).

Responsibility for the creation of a society free from sexual discriminations should not just be placed on social parties, but also other establishments such as families, institutions, and the state itself. Among these, Blaya, Debarbieux and Lucas (2007) emphasize the co-educative school; the role of schools is crucial in order to challenge the usual gender perspectives, and to develop a new gender culture based on respect towards differences and balanced and equal relationships among students.

Since the 1980s, there have been several studies about homosexuality and education. Within mixed schools, it is suggested PE is one of the areas which can be improved on greatly (Ayvazo and Sutherland 2009). Past research has argued the most hostile climate towards homosexuality can often be found in PE (Hemphill and Symons 2009; McCaughtry, Dillon, Jones, and Smigell 2005; O'Brien, Shovelton, and Latner 2013). Moreover, the increase in sport practice, as well as its extended presence in mass media, may mean more boys and girls are influenced and imbued by this gender order. As Ayvazo and Sutherland (2009) and Dowling (2013) state, stereotypical views of homophobia and heterosexuality, as well as of masculinity and femininity, have historically been, and continue to be, emphasized within sport contexts.

Within the field of PE, several initial studies in the nineties (Clarke, 1998; Griffin, 1991; Sykes, 1998) show the existence of discriminatory situations, leading homosexual teachers to hide their sexualities (Devís, Fuentes and Sparkes 2005). As Sykes (2001) indicates, they are silenced by heteronormativity. Other researchers (Brackenridge, Rivers, Gough, and Llewellyn, 2007; Clarke 2006a; García 2011; Sykes 2004) have highlighted that the most basic (but frequent) way to oppress and bully gays and lesbians at school, and in PE lessons specifically, is 
the use of abusive language. Additionally the stereotypes bound to homosexuality, such as promiscuity, have in some cases led to harassment and discrimination towards gay teachers, who may be regarded as perverted due to working with children (Lenskyj 1997; Sparkes 1994). In order to avoid this, lesbian PE teachers may aim to develop traditionally feminine attributes, in a bid to achieve what is known as hyper-femininity (Clarke 1998; Lenskyj 1994). In many cases, gay and lesbian teachers admit having more distant relationships with their students than heterosexual teachers in order to avoid suspicions (Clarke 2002). In spite of the social and legal improvements, gays and lesbians are still subject to abusive behaviour and are often victims of negative attitudes in the field of PE (White et al. 2010).

Research analyzing mixed-sex schools and PE teachers' views towards homosexuality is also apparent within the literature. Morrow and Gill (2003) observed PE teachers' perceptions of homophobia, finding homophobic behavior is common in secondary schools and colleges in the United States and that teachers, according to students (Gill, Morrow, Collins, Lucey, and Scultz 2006; 2010), often do not manage to create an inclusive atmosphere in their lessons. Students emphasize the dominance of heteronormativity in PE lessons, forcing boys and girls to act in specific gendered ways which are placed within the boundaries of heterosexuality (Clarke 2002), in order to be regarded as normal (Larsson, Redelius, and Fagrell 2011). Similarly, Piedra, Rodríguez-Sánchez, Ries, and Ramírez-Macías' research (2013) points out, according to students, that PE teachers are often unaware of homophobia in class and that they take little action to overcome possible discriminatory situations in their lessons.

In their study about sexual sensitivity at school, American researchers McCaughtry et al. (2005), and others previously (Clarke 1998; Lenskyj 1997; Squires and Sparkes 1996), acknowledge the important role of PE teachers as implied agents in the change of sensitivity, in the acknowledgement of gays and lesbians' rights. In their review of studies regarding homophobia in PE lessons, Ayvazo and Sutherland (2009), as well as Clarke (2006b), deal with some actions to eliminate homophobia: teaching respect towards others in lessons, giving value to different sexual orientations, and showing inclusive behavior in their classrooms. Accordingly, they suggest the need to change PE teachers' future training in order to ensure inclusive environments are fostered, in turn reducing negative attitudes in classrooms (Saraç 2012). However, many teachers prefer to ignore issues occurring at school related to homophobic discrimination in order to avoid further problems and abuse. 
Finally, several studies suggest including education on homophobia within the academic curriculum, which may improve inclusivity in mixed classrooms (Toomey, McGuire, and Russell, 2012). Unfortunately, there is still opposition in treating this matter openly in some areas of PE (Lenskyj, 1997; Piedra, Ramírez-Macías, and Latorre, 2014); some teachers argue that dealing with social issues is not part of their job in the classroom.

In recent years, there have been other studies in the Anglo-Saxon scientific sphere which contest the existence of negative attitudes towards gays and lesbians in society, mainly among the younger generation (McCormack, 2012; Savin-Williams, 2005). This research shows some evidence of a decline in homophobia in sport thanks to legal and social advances (Anderson 2009). In spite of the shortage of research specific to PE in Spain, recent studies elsewhere do indicate that PE is becoming more accepting of sexual diversity (Anderson, 2012). In sport, athletes are less afraid to state their sexual orientation (Anderson, 2011; Anderson and Bullingham, 2013), teammates accept gay athletes on their teams (Adams and Anderson, 2012; Margrath, Anderson, and Roberts, in press), coaches better manage the presence of gays and lesbians on their teams (Oswalt and Vargas, 2013), and supporters and mass media show more signs of respect and tolerance towards gay athletes (Cashmore and Cleland, 2012; Cleland, 2014; Nylund, 2014). Similarly, homosexually-themed language that may have previously been regarded as an oppression instrument may now be perceived as non-pejorative (McCormack 2011).

Due to the scarcity of previous research, this study will be an important addition to the literature on Spanish PE, increasing current knowledge of the culture of PE for gays and lesbians. Furthermore, it will facilitate a better understanding of the levels of homohysteria and inclusivity in PE in Spain.

\section{Materials and method}

This study used an experimental and cross-sectional descriptive design, using the survey technique (applied in the second semester of 2011-2012 academic year) in order to assess Spanish PE teachers' perceptions of homophobia and heterosexism in their lessons.

\section{Sample}


The sample was composed of 170 PE teachers from primary, secondary and pre-university education in mixed schools. The participants teach PE in different cities in the autonomous communities of Andalusia $(n=117)$ and Galicia $(n=50) .3$ participants did not indicate their geographical background.

The sampling was non-probabilistic (incidental) as the questionnaire was only applied to those PE teachers who could be contacted. The contact procedure was completed electronically (with an online form supplied by email) or in person. All the participants answered the survey on a voluntary basis, previously signing a consent form in which anonymity and data confidentiality were guaranteed. In total, 13 participants answered online and 157 using the paper version.

Regarding the participants, 106 were men and 64 women, with $49.7 \%$ working in primary education, $36.2 \%$ in compulsory secondary education and $14.1 \%$ in pre-university studies. Participants' average age was $40.6 \pm 8.5$ years old. In order to avoid excessive data dispersion, they have been grouped into age ranges. Thus, the highest percentages of participants are found in the 31 to 40 and 41 to 50 age groups (42.4\% and $30.6 \%$, respectively). The rest of the participants are within the 20 to $30(11.8 \%)$ and 51-60 age ranges (15.3\%). 45.9\% have been teaching for more than 15 years, 38.8\% have between 5 and 15 years of teaching experience and $15.3 \%$ have less than 5 years. Concerning the educative teaching context, $85.1 \%$ of the teachers work in public schools, compared to $14.9 \%$ in private or semi-private schools.

Regarding the participants' sexual orientation, most of them define themselves as heterosexuals (96.4\%); homosexuals stand for $2.4 \%$ and 'other sexual orientation' has the lowest value with $1.2 \%$. Concerning sex, $97.1 \%$ of men and $95.2 \%$ of women declare being heterosexual. There are similar figures in the number of teachers declared homosexual in both sexes; $1.9 \%$ of men and $3.2 \%$ of women (two instances each), as well as $1 \%$ of men and $1.6 \%$ of women in the category 'other sexual orientations' (one instance each).

\section{Instruments}

In order to measure perceptions of homophobia and heterosexism in PE, the questionnaire created by Morrow and Gill (2003) was used. The original instrument is composed of three constructs: homophobic, heterosexist, and inclusive behavior. It consists of 16 items and the first 11 are answered on a 4-point Likert scale with the last 5 items on a 5-point Likert scale.

A specific section with questions regarding participants' profile (sex, age, sexual 
orientation, geographical location) was included. Teachers also indicated the type of school (public, semi-private, or private) and the educative level they were teaching in (primary, compulsory secondary, or pre-university education). Finally, they were asked about the number of years they had been teaching, and their participation in activities or tasks related to coeducation.

In order to clarify concepts within the questionnaire, the following definitions were included in the initial section:

- Heterosexist behavior: Behavior that assumes all students and teachers are heterosexual, and declarations/ activities that presume everyone lives in a traditional family or goes out with someone from the opposite sex.

- Homophobic behavior: Abuses or physical aggressions addressed to people who are believed to be gay or lesbian, or to people or institutions who support gays and lesbians.

- Inclusive behavior: This behavior deliberately embraces everyone, including gays and lesbians.

In order to deal with questionnaire reliability and data analysis, SPSS 22.0 for Windows was used. Accordingly, the use of chi-square was considered for significance tests, as well as Cohen's $d$ to calculate size effect.

\section{Translation}

In order to translate the original questionnaire, a back-translation technique (Sperber, 2004) was used. Before its translation, the 16 items were analyzed according to their readability, scope and comprehension. Four Spanish native speakers, all specialists in PE, translated the items from English into Spanish separately. The existing differences among the translated versions were discussed in order to get an initial version of the questionnaire in Spanish. Four English native speakers later translated this Spanish version into English. In order to reach an agreement among the translated versions, translators proof-read them again. Then, comparability and interpretation similarities (Sperber 2004) of the original text and the back-translations were discussed and the differences found were corrected. Furthermore, translated versions were given to the four bilingual PE teachers, who were not familiar with the original English version, so that they could translate the Spanish items into English. Both the original English version and the back-translated 
one were compared again in order to determine any significant differences.

\section{Internal consistency of the instrument}

Once the questionnaire was translated, a pilot sample was performed with 30 male and female PE teachers in Andalusia who work in mixed-sex schools. The initial reliability reached a Cronbach's $\alpha=.553$. Item 16 was eliminated in the teachers' scale and the reliability increased up to Cronbach's $\alpha=.640$. After final data collection, reliability was calculated again. Cronbach's alpha coefficient increased slightly up to .710. It should be noted that McMillan (2008) admits an acceptable reliability level between $\alpha=.700$ and .900 .

\section{Results}

The results of the responses to the 15 items that compose the questionnaire are shown in the following tables:

\section{[Table 1: Relative frequencies about teachers perceptions of homophobic and heterosexist} behaviors]

Response polarization among teachers was noticed when asked about perceived heterosexist behaviors amongst students. $79.3 \%$ of the responses are found in the two highest values of Likert scale (41.4\% answer 'many' and 37.9\% answer 'some'). This data contrasts with the data refers to the observation of students' heterosexist behaviors towards teachers, in which greater response dispersion is observed.

Taking this response polarization into account, the sum of those who have witnessed more homophobic behaviors amongst students is $55.9 \%$ (adding the percentages of 'many' and 'some'), as opposed to the $44 \%$ who point out having witnessed fewer situations ('few' and 'never'). Similarly noticeable is the quantity of students' homophobic behaviors towards other students which occurs on a less regular basis ( $83.4 \%$ adding 'few' and 'never'), with no students reported to address homophobic behaviors towards teachers: $89.3 \%$ of teachers indicate they have never observed this behavior from students and $91 \%$ of students have never observed this behavior from teachers.

\section{[Table 2: Relative frequencies about teachers' use of inclusive behavior]}


Regarding the results obtained in the third construct, of relevance is the use of inclusive language where more than $60 \%$ of teachers answer with one of the two highest values. Nonetheless, very few regard gay people as role-models. The very high number of participants who answer with the two highest values (87\%) when dealing with homophobic behaviors is also noticeable. However, this percentage reduces to $56 \%$ when asked about the creation of safe spaces by teachers. In the second part of the results section the most relevant data obtained from the contingency analysis among the questionnaire items and the sex/ sexual orientations of surveyed teachers will be explored.

\section{[Table 3: Teachers perceptions of homophobic and heterosexist behaviors according to} gender]

\section{[Table 4: Teachers' use of inclusive behavior according to gender]}

There were differences in regards to gender concerning the frequency of actions against student's homophobia (item 5), with this number higher in men $(p=.040, d=-.344)$. Another relevant finding is the difference ( $p=.033, d=-.465$ ) found in the use of sexist remarks (item 9 ). Male teachers make a greater use of these remarks compared to female teachers.

\section{[Table 5: Teachers perceptions of homophobic and heterosexist behaviors according to sexual orientation]}

\section{[Table 6: Teachers' use of inclusive behavior according to sexual orientation]}

Analyzing responses regarding teachers' sexual orientation, it is necessary to observe differences ( $p=.007, d=-.869)$ noticed among heterosexual and homosexual people regarding homophobic behaviors by their classmates (item 6). The same trend is observed in item 7, concerning the existence of colleagues' heterosexist behaviors, in which there are significant differences ( $p=.005, d=-.835$ ) among heterosexuals and homosexuals. The last significant item is 12 , concerned with the use of inclusive language. There are significant differences in the answers given by heterosexuals and those under the term 'others' ( $p=.038, d=-.635)$ and homosexuals and others ( $p=.05, d=.0$ ). Regarding these statements, it must be remembered that the reduced sample of those in the homosexual (4) and 'other sexual orientation' categories (2), compared to those declared heterosexual (149), limits the result's generalization. Nevertheless, it is necessary to point these differences out to aid further research, and provide a comprehensive 
review in order to later confirm or reject the results.

\section{Discussion}

When reviewing the literature, two lines of analysis within the area of homosexuality, sport and PE have been raised. One of the lines argues PE is a subject that emphasizes the traditional gender order most, and one in which gay men and lesbian women are consistently isolated and stigmatized. Studies by Ayvazo and Sutherland (2009), Hemphill and Symons (2009), McCaughtry et al. (2005) and O'Brien et al. (2013) highlight the hostile atmosphere for homosexuals in PE and, of course, towards other sexual orientations which differ from heterosexuality (Pérez-Samaniego, Fuentes, Pereira, and Devís, in press). In Spain, studies undertaken with young students indicate that this is the current trend due to the hierarchy of the traditional gender order (Venegas, 2013) which is still being reproduced. Conversely, some of the most recently published studies (Adams and Anderson, 2012; Anderson, 2011; Cleland, 2014; Nylund, 2014; Oswalt and Vargas, 2013) indicate a more tolerant society, in which homophobia is decreasing among athletes, coaches and journalists within sport. Nevertheless, this social change is not described in the context of Spanish society (Piedra et al. 2013).

The role of PE teachers is fundamental in creating inclusive environments. The results obtained in the present research show that male and female PE teachers in mixed schools are quite aware of the existing discrimination in their lessons. In fact, more than $75 \%$ claim having witnessed 'many' or 'some' types of heterosexist behavior among students and also within the highest values in this scale, more than 55\% have answered that they have witnessed homophobic behavior among their students. Furthermore, most teachers claim that they face these discriminatory situations by themselves in their classrooms. However, teachers do not always take action to fight against discrimination, since there are few teachers using inclusive language and creating safe spaces in their PE lessons.

This is supported by past research by Piedra et al. (2013) who conclude that Spanish teachers are less aware of discriminatory situations and, therefore, they take little action to change this situation. Gill et al. (2010) found similar results within an American context. It is important to recognize that there are different perceptions between young people and adults about inclusion and discrimination. McCormack, Anderson and Adams (2014) explain how the reduction of cultural homophobia and changes in the social organization of masculinity are 
affected by age. Nevertheless, despite the apparent contradictions between the present study and Piedra et al. (2013), it is true that both have similar results regarding homophobic and heterosexist behaviors among male and female students. Both reach similar results on the existence of homophobic and heterosexist behaviors among students (from both students' and teachers' views). Thus, in spite of students' opinions on the level of teacher awareness on homophobia and heterosexism, it is noticeable that there is a high level of concurrence among teachers and students when perceiving these kinds of behaviors. Thus, in line with Morrow and Gill (2003), this research indicates PE teachers are well aware of the existence of homophobic and heterosexist behaviors in PE. Hence, the present study, together with others undertaken in the Spanish context (Piedra et al., 2014; Piedra et al., 2013; Pérez-Samaniego et al., in press) suggest Spain is still deeply rooted in the heteronormative gender order, as opposed to decreasing homophobia as observed in other societies. Many countries, like the United Kingdom, Australia and the USA, have experienced social changes brought about by new legislation, public awareness campaigns, and the presence of more openly gay athletes. Spain has also started to modify its legislation; however, due to the lack of sports-specific laws and awareness campaigns, it is rare for athletes to declare their sexuality openly in public, thus contributing to the idea that homosexuality is a taboo subject in sport.

Two factors are highlighted concerning students' heterosexist and homophobic behaviors towards PE teachers. Firstly, clear differences between these behaviours are apparent, as there is a relevant dispersion in the case of heterosexist behaviors and a clear concentration of homophobic behaviors in the values 'few' and 'never'. This could be due to the idea that heterosexism may still be perceived as 'normal' and not necessarily linked to discriminatory behaviour. However, there is higher awareness on the pejorative and degrading nature of homophobic behavior. Conversely, prudence towards homophobia may be apparent amongst teachers as most have never witnessed students' homophobic behaviors towards other teachers. This may be due to the fact that teachers are not 'equal' with students, and their position of public authority may limit their public expression.

Nonetheless, it is important to examine more deeply the apparent prudence of students' homophobic behaviors towards teachers. Heterosexuals are more aware of these kinds of behaviors; no homosexuals and only one person under 'other sexual orientation' claimed having witnessed students' homophobic behaviors towards teachers. When asked if they have been 
victims of students' or colleagues' homophobic behaviors, none of the gay or lesbian respondents answered that they had suffered from this behavior 'many' or 'some' times.

It could be that these teachers aim to hide their sexual orientation, to minimize suspicion or stigmatization by other teachers and students. This hypothesis is supported by the results of several other studies such as Devís et al. (2005), Sykes (2001), Clarke (2002), Wyatt and Peterson (2010), and Saraç (2012). This would again reinforce the hypothesis that in Spain there are still high levels of homohysteria. However, the ability to generalize these results is limited by the small sample of gay and lesbian PE teachers in this research (6 people in total).

Nonetheless, significant differences among men and women were found in relation to the effects of students' homophobic behavior (in this instance the number of respondents is not a limiting factor due to the large sample of both sexes), with men more likely to be victims of these behaviors. These findings reinforce the connections between homophobia and the traditional gender order. This data reinforces the idea that male homosexuality is often more stigmatized than female homosexuality in the area of PE, often due to narrow definitions of masculinity and ideas that male athleticism and homosexuality are incompatible. Traditional gender roles and gender stereotyping are the basis of the established gender order; men and women are expected to behave in different ways specific to their gender, with homosexuality for men considered contradictory to a masculine athletic identity (Connell, 1986). Because of this, male sport is often especially hostile to homosexuality (Anderson, 2002; Roper and Halloran, 2007). In contrast, women who play sport (particularly contact sports or those considered aggressive) are often considered to be unfeminine and therefore lesbian. However, in Spain there is currently no accurate data to confirm this. Based on previous studies in other contexts, an initial hypothesis may be the lower persecution of lesbian women compared to gay men in Spanish PE.

In summary, our research indicates teachers are often aware of the existing problems related to homophobia and heterosexism in their PE lessons. Furthermore, they are often conscious that these problems can affect themselves as well as their students. Taking this into consideration, a question arises: What can they do? In regards to homosexually-themed language, often the main source of heteronormativity, surveyed teachers indicated they mostly did not use homophobic or sexist remarks and aimed to use politically correct language. Moreover, most indicated they did not automatically consider heterosexuality the norm. As stated, there are also 
significant differences among men and women, with the use of sexist and homophobic remarks more frequent for male than female teachers. It could be argued men are more likely to authorize traditional notions of gender, and displays of homophobia may be regarded as a means to express masculine values to ensure they remain dominant.

Ultimately, the main instrument for stigmatization against gays and lesbians in societies with high levels of homohysteria is language. Teachers in this study indicate their language is mostly free from any heteronormative influence. In itself, this is fundamental to create an inclusive atmosphere in PE lessons. Nevertheless, Piedra et al. (2013) and Gill et al. (2010) suggest that, according to students, PE teachers do not fully achieve a safe and inclusive space in their lessons. Teachers in our research stated that they are careful regarding their use of language, but there are limitations to this questionnaire data, including the fact participants may have answered in a 'politically correct' way. Is it possible that we are in a society with high levels of homohysteria but some factors, such as use of inclusive language, indicate a shift towards a more gay-friendly culture? This remarkable divergence between students' and teachers' views requires more research using a variety of different data collection methods. This would allow a clearer definition of how homophobia and heterosexism are manifested in PE, in order to create effective solutions.

To conclude, teachers and students are aware of heterosexist and homophobic behaviors that homosexual students receive. There are still developments to be made to take efficient action so male and female students, regardless of sexuality, can feel included in PE (Larsson et al. 2011). Moreover, further research is needed to explore homophobia and heterosexism for nonheterosexual teachers, as there is currently little awareness of the levels of homophobia and heterosexism they receive.

\section{Conclusions and prospects}

This study aimed to describe the perceptions of homophobia and heterosexism within the PE community in Spain. The research shows teachers are conscious of homophobia and heterosexism, and have witnessed these behaviors among students in their lessons. However, the research indicates teachers do not perceive these behaviours to be apparent from students towards teachers. The teachers participating in the present study claim to take action when discriminatory behavior occurs in their lessons. However, fewer teachers claim they proactively take steps to 
prevent these behaviors occurring in the first place. It must be noted, however, that the scarce sample of gay and lesbian teachers in this study means these findings are not conclusive. For this reason, future studies should aim to increase the amount of gay and lesbian teachers participating.

Moreover, data shows that homosexually-themed language is still a well-used instrument in classrooms to discriminate against gays and lesbians. Some teachers are not fully aware of its effect, since many do not use inclusive language in their teaching practice, with homosexuallythemed language more prominent amongst male teachers. Future studies should consider the effect of social desirability for PE teachers; participants may not always answer truthfully with the use of questionnaires, and other methodologies that help to overcome this should be considered. Potentially, qualitative methods, such as extended observations of the PE environment may be useful. Finally, this research area could widen to include comparisons with other countries and cultures to enrich current knowledge, and consider a wide variety of initiatives and solutions to create a welcoming environment for gays and lesbians within PE.

\section{References}

Adams, A., and Anderson, E. 2012. "Exploring the relationship between homosexuality and sport among the teammates of a small Midwestern Catholic College soccer team." Sport, Education and Society 17(3): 347-363. doi:10.1080/13573322.2011.608938

Anderson, E. 2002. "Openly gay athletes. Contesting hegemonic masculinity in a homophobic environment." Gender \& Society 16(6): 860-877. doi: 10.1177/089124302237892

Anderson, E. 2009. Inclusive masculinity: the changing nature of masculinities. New York: Routledge.

Anderson, E. 2011. "Updating the outcome. Gay athletes, straight teams, and coming out in educationally based sport teams." Gender \& Society 25(2): 250-268. doi: $10.1177 / 089124310396872$

Anderson, E. 2012. "Inclusive masculinity in a physical education setting." Journal of Boyhood Studies 6(2): 151-165. doi: 10.3149/thy.0602.151

Anderson, E., and Bullingham, R. 2013. "Openly lesbian team sport athletes in an era of decreasing homohysteria." International Review for the Sociology of Sport Online First, 114. doi:10.1177/1012690213490520

Ayvazo, S., and Sutherland, S. 2009. "Uncovering the secrets: Homophobia in Physical 
Education." Action in Teacher Education 31(3): 56-69. doi:10.1080/01626620.2009.10463528.

Blaya, C., Debarbieux, E., and Lucas, B. 2007. "La violencia hacia las mujeres y hacia otras personas percibidas como distintas a la norma dominante: el caso de los centros educativos." Revista de Educación 342: 61-81.

Brackenridge, C., Rivers, I., Gough, B., and Llewellyn, K. 2007. "Driving down participation. Homophobic bullying as a deterrent to doing sport." In Sport \& Gender identities. Masculinities, femininities and sexualities edited by C.C. Aitchison, 122-138. London, UK: Routledge.

Cashmore, E., and Cleland, J. 2012. "Fans, homophobia and masculinities in association football: evidences of a more inclusive environment." The British Journal of Sociology 63(2): 370387. doi:10.1111/j.1468-4446.2012.01414.x

Clarke, G. 1997. "Playing a part: the lives of lesbian physical education teachers." In Researching women and sport, edited by G. Clarke, and B. Humberstone, 36-49. New York: Palgrave.

Clarke, G. 1998. "Queering the Pitch and coming out to play: lesbians in Physical Education and Sport.” Sport, Education and Society 3(2): 145-160. doi:10.1080/1357332980030202.

Clarke, G. 2002. "Difference matters: sexuality and physical education." In Gender and Physical Education. Contemporary issues and future directions, edited by D. Penney, 41-56. New York: Routledge.

Clarke, G. 2006a. "There's nothing queer about difference. Challenging heterosexism and homophobia in Physical Education." In Equity and Inclusion in Physical Education and Sport, edited by S. Hayes, and G. Stidder, 91-104. London: Routledge.

Clarke, G. 2006b. "Sexuality and Physical Education.” In The Handbook of Physical Education, edited by D. Kirk, D. MacDonald, and M. O’Sullivan, 723-739. London: SAGE.

Cleland, J. 2014. "Racism, Football Fans, and Online Message Boards: How Social Media Has Added a New Dimension to Racist Discourse in English Football”. Journal of Sport \& Social Issues 38(5): 415-431. doi:10.1080/02614367.2010.541481

Connell, R.W. 1986. “Theorising Gender." Sociology 19(2): 260-272. Doi: $10.1177 / 0038038585019002008$

Connell, R.W. 1995. Masculinities. Cambridge: Polity Press 
Devís, J, Fuentes, J., and Sparkes, A.C. 2005. “¿Qué permanece oculto del currículum oculto? Las identidades de género y de sexualidad en la educación física." Revista Iberoamericana de Educación 39: 73-90.

Dowling, F. 2013. "Teacher educators' gendered workplace tales." In Gender and Sport. Changes and Challenges, edited by G. Pfister, and M.K. Sisjord, 217-231. Münster: Waxmann.

Dreyer, Y. 2007. "Hegemony and the internalization of homophobia caused by heteronormativity." HTS Theological Studies 63(1): 1-18. doi: 10.4102/hts.v63i1.197

European Association of Single-Sex Education (EASSE). 2010. "España.” Accessed December 26. http://www.easse.org/es/country/es/Espa\%C3\%B1a.

García, C. 2011. "Gender Expression and Homophobia: a motor development and learning perspective." Journal of Physical Education, Recreation \& Dance 82(8): 47-49. doi:10.1080/07303084.2011.10598678.

Gill, D.L., Morrow, R.G., Collins, K.E., Lucey, A.B., and Scultz, A.M. 2010. "Perceived Climate in Physical Activity Settings." Journal of Homosexuality 57(7): 895-913. doi: 10.1080/00918369.2010.493431.

Gill, D.L., Morrow, R.G., Collins, K.E., Lucey, A.B., and Scultz, A.M. 2006. "Attitudes and sexual prejudice in sport and physical activity." Journal of Sport Management 20: 554-564.

Griffin, P. 1991. "Identity management strategies among lesbian and gay educators." Qualitative Studies in Education 4(3): 189-202. doi:10.1080/0951839910040301.

Hemphill, D., and Symons, C. 2009. "Sexuality Matters in Physical Education and Sport Studies." Quest 61(4): 397-417. doi:10.1080/00336297.2009.10483623.

Herek, G.M. 1996. "Heterosexism and homophobia." In Textbook of homosexuality and mental health, edited by R. Cabaj, and T. Stein, 101-113. Arlington, VA: American Psychiatric Association.

Hyde, S., and Delamater, I.D. 2006. Understanding human sexuality. 9th ed. Boston, MA: McGraw-Hill.

Kian, E.M., Anderson, E., Vincent, J., \& Murray, R. 2013. “Sport journalists' views on gay men in sport, society, and within sport media." International Review for the Sociology of Sport. Online First, doi: 10.1177/1012690213504101

Larsson, H., Redelius, K., and Fagrell, B. 2011. "Moving (in) the heterosexual matrix. On 
heteronormativity in secondary school physical education." Physical Education and Sport Pedagogy 16(1): 67-81. doi:10.1080/17408989.2010.491819.

Lenskyj, H.J. 1994. "Sexuality and femininity in sport contexts: issues and alternatives." Journal of Sport and Social Issues 18(4): 356-376. doi: 10.1177/019372394018004005.

Lenskyj, H.J. 1997. "No fear? Lesbians in sport and physical education." Women in Sport and Physical Activity Journal 6: 7-22.

Lenskyj, H.J. 2013. "Reflections on communication and sport: on heteronormativity and gender identities.” Sport \& Communication 1(1/2): 138-150. doi: 10.1177/2167479512467327

Margrath, R., Anderson, E., \& Roberts, S. In press "On the door-step of equality: Attitudes toward gay athletes among academy-level footballers". International Review for the Sociology of Sport, Online First, 1-18. doi: 10.1177/1012690213495747

McMillan, J.H. 2008. Assessment Essentials for Standards-Based Education. New York: Corwin Press.

McCaughtry, N., Dillon, S.R., Jones, E., and Smigell, S. 2005. "Sexuality sensitive schooling." Quest 57(4): 426-443. doi:10.1080/00336297.2005.10491865.

McCormack, M. 2011. "Mapping the Terrain of Homosexuality-Themed language." Journal of Homosexuality 58(5): 664-679. doi:10.1080/00918369.2011.563665.

McCormack, M. 2012. The Declining Significance of Homophobia. How Teenage Boys are Redefining Masculinity and Heterosexuality. Oxford, UK: Oxford University Press.

McCormack, M., Anderson, E., and Adams, A. 2014. "Cohort Effect on the Coming Out Experiences of Bisexual Men.” Sociology 48(6): 1207-1223. doi: $\underline{10.1177 / 0038038513518851}$

McCormack, M., and Anderson, E. 2014. "Homohysteria: Definitions, context and intersectionality." Sex Roles 71: 152-158. doi: 10.1007/s11199-014-0401-9

Ministerio de Educación, Cultura y Deporte. 2014. "El ministro de Educación, Cultura y Deporte, José Ignacio Wert, presenta el informe 'Datos y cifras. Curso escolar 2014-2015'.” Ministerio de Educación, Cultura y Deporte, September 15. http://www.mecd.gob.es/prensamecd/actualidad/2014/09/20140915-datos.html.

Morrow, R.G., and Gill, D.L. 2003. "Perceptions of homophobia and heterosexism in Physical Education." Research Quarterly for Exercise and Sport 74(2): 205-214. doi:10.1080/02701367.2003.10609082. 
Nylund, D. 2004. "When in Rome: Heterosexism, homophobia, and sports talk radio." Journal of Sport \& Social Issues 28(2): 136-168. doi: 10.1177/0193723504264409

Nylund, D. 2014. "Transmitting softer masculinity. Sports talk radio and masculinity" In Routledge Handbook of Sport, Gender and Sexuality, edited by J. Hargreaves, and E. Anderson, 453-460. London: Routledge.

O'Brien, K.S., Shovelton, H., and Latner, J.D. 2013. "Homophobia in physical education and sport: The role of physical/sporting identity and attributes, authoritarian aggression, and social dominance orientation." International Journal of Psychology 48(5): 891-899. doi:10.1080/00207594.2012.713107.

Oswalt, S.B., and Vargas, T.M. 2013. "How safe is the playing field? Collegiate coaches' attitudes towards gay, lesbian, and bisexual individuals." Sport in Society 16(1): 120-132. doi:10.1080/17430437.2012.690407

Pérez-Samaniego, V., Fuentes, J., S., Pereira, S., and Devís, J. In press. “Abjection and alterity in the imagining of transgender in physical education and sport: a pedagogical approach in higher education." Sport, Education and Society. doi: 10.1080/13573322.2014.981253.

Pharr, S. 1997. Homophobia: a weapon of sexism. Inverness, CA: Chardon Press.

Piedra, J., García-Pérez, R., Fernández-García, E., and Rebollo, M.A. 2014. "Gender gap in physical education: teachers' attitudes towards equality." Revista Internacional de Medicina y Ciencias de la Actividad Física y el Deporte 14(53): 1-21.

Piedra, J., Ramírez-Macías, G., and Latorre, A. 2014. "Visibilizando lo invisible: Estudio de casos de las creencias del profesorado de educación física sobre homofobia y masculinidades." Retos Nuevas tendencias en Educación Física, Deporte y Recreación 25: $36-42$.

Piedra, J., Rodríguez-Sánchez, A.R., Ries, F., and Ramírez-Macías, G. 2013. "Homofobia, heterosexismo y educación física: percepciones del alumnado.” Profesorado. Revista de Currículum y Formación del Profesorado 17(1): 325-338.

Plummer, D. 1999. One of the Boys: Masculinity, Homophobia and Modern Manhood. New York: Harrington Park Press. 
Roper, E., and Halloran, E. 2007. "Attitudes Toward Gay Men and Lesbians Among Heterosexual Male and Female Student-Athletes." Sex Roles 57(11-12): 919-928. doi: $10.1007 / \mathrm{s} 11199-007-9323-0$

Saraç. L. 2012. "Attitudes of future physical education teachers in Turkey toward lesbians and gay men.” Psychological Reports 111, 765-775. doi:10.2466/11.06.21.PR0.111.6.765-775.

Savin-Williams, R. C. 2005. The new gay teenager. Cambridge, MA: Harvard University Press.

Scraton, S. 2013. "Feminism and Physical Education: does gender still matter?" In Gender and Sport. Changes and Challenges, edited by G. Pfister, and M.K. Sisjord, 199-216. Münster: Waxmann.

Sparkes, A.C. 1994. "Self, silence and invisibility as a beginning teacher: A life history of lesbian experience." British Journal of Sociology of Education 15: 93-118. doi:10.1080/0142569940150106.

Sperber, A.D. 2004. "Translation and Validation of Study Instruments for Cross-Cultural Research.” Gastroenterology 124: S124-S128. doi:10.1053/j.gastro.2003.10.016.

Squires, S. I., and Sparkes, A. C. 1996. "Circles of silence: Sexual identity in physical education and sport." Sport, Education and Society 1: 77-101. doi:10.1080/1357332960010105.

Sykes, H. 1998. "Turning the closets inside/out: Towards a queer-feminist theory in women's physical education." Sociology of Sport Journal 15, 154-173.

Sykes, H. 2001. "Understanding and overstanding: Feminist-poststructural life histories of physical education teachers." Qualitative Studies in Education 14(1): 13-31. doi:10.1080/0269172001009744.

Sykes, H. 2004. "Pedagogies of censorchip, injury and masochism: teacher responses to homophobic speech in physical education." Journal of Curriculum Studies 36: 75-99. doi:10.1080/0022027032000148306.

Toomey, R. B., McGuire, J. K., and Russell, S. T. 2012. "Heteronormativity, school climates, and safety for gender nonconforming students." Journal of Adolescence 35: 187-196. doi:10.1016/j.adolescence.2011.03.001.

Venegas, M. 2013. "Sex and relationships education and gender equality: recent experiences from Andalusia (Spain).” Sex Education: Sexuality, Society and Learning 13(5): 573-584.

Vicente, M. 2010. "Educación física e ideología. Creencias pedagógicas y dominación cultural en las enseñanzas culturales del cuerpo." Retos. Nuevas tendencias en Educación Física, 
Deporte y Recreación 17: 76-85.

Vidiella, J. 2007. "El deporte y la actividad física como mediadores de modelos corporales: género y sexualidad en el aprendizaje de las masculinidades." Educación Física y Ciencia 9: $1-20$.

White, C.S., Oswalt, S.B., Wyatt, T.J., and Peterson, F.L. 2010. "Out on the Playing Field: Providing Quality Physical Education and Recreational Opportunities for Lesbian, Gay, and Bisexual Youth.” Physical Educator 67(1): 46-56. 